\title{
Using the MoodleReader as an Extensive Reading Tool and its Effect on Iranian EFL Students' Incidental Vocabulary Learning
}

\author{
Sepideh Alavi (Corresponding author) \\ Shiraz University, Iran \\ Department of Foreign Languages and Linguistics, School of Literature and Humanities \\ Eram University Complex, Shiraz, Iran \\ Tel: 98-711-623-1399Ｅ-mail: salavi@rose.shirazu.ac.ir
}

Afsaneh Keyvanshekouh

Shiraz University, Iran

Department of Foreign Languages and Linguistics, School of Literature and Humanities

Eram University Complex, Shiraz, Iran

E-mail: afsoon_ksh@yahoo.com

Received: March 27, 2012

Accepted: April 15, 2012

Published: June 1, 2012

doi:10.5539/elt.v5n6p135

URL: http://dx.doi.org/10.5539/elt.v5n6p135

This research was funded and supported by the Shiraz University Research Committee.

\begin{abstract}
The present study focused on using the MoodleReader to promote extensive reading (ER) in an Iranian EFL context, emphasizing its effect on students' incidental vocabulary acquisition. Thirty eight Shiraz University sophomores were assigned to experimental and control groups. The experimental group used the MoodleReader for their ER program, while the control group followed the traditional ER curriculum, reading a small number of pre-assigned graded readers during the semester. Both groups were given Production and Recognition Vocabulary Levels Tests before and after the experiment. T-tests showed that using the MoodleReader improved the experimental group's incidental vocabulary acquisition, having a stronger effect on production as compared to recognition vocabulary. Linear regression analyses were also run to determine the relationship between incidental vocabulary acquisition and the learners' use of vocabulary learning strategies. The results indicated a significant relationship between the experimental group's vocabulary production and their use of vocabulary learning strategies.
\end{abstract}

Keywords: Extensive reading, MoodleReader, Incidental vocabulary learning, EFL learners

\section{Introduction}

Vocabulary is believed to be the essence of a language since the language learners' mastery of vocabulary determines to a great extent their second/foreign language proficiency. Moreover, without words speakers will not be able to communicate with each other. As Schmitt (2008) puts it, "Learners need large vocabularies to successfully use a second language, and so high vocabulary targets need to be set and pursued" (Schmitt, 2008, p. 353).

As the status of vocabulary has improved in language teaching and learning, more attention is being paid to research on vocabulary acquisition as well (Day, Omura, and Hiramatsu, 1991; Hamzah, Kafipour, and Abdullah, 2009; Nakata, 2006; Pigada, and Schmitt, 2006), encouraging both ESL/EFL teachers and learners to find ways of promoting vocabulary acquisition.

Nation (1997) recognizes the major problem in teaching vocabulary being the small number of words language teachers can cope with at any given time. Teachers can deal with this limitation, he continues, by involving the learners in incidental vocabulary learning from listening or reading comprehension tasks. Hence, a distinction is made between incidental and intentional vocabulary learning.

\subsection{Intentional and Incidental Vocabulary Learning}

Several scholars have made a distinction between the two prominent methods of acquiring new vocabulary, namely 
intentional (explicit) and incidental (implicit) learning. Ellis (1995) for example, states that "intentional learning requires focal attention to be placed deliberately on the linguistic code (i.e., on form or form-meaning connections)," while "incidental learning requires attention to be placed on meaning (i.e., message content) but allows peripheral attention to be directed at form" (p. 14). He further goes on to mention that implicit vocabulary learning is the unconscious acquisition of new words due to repeated exposure. Such process of language acquisition is similar to incidental learning, during which, according to Chen (2009), the learners are not aware of the learning purpose before completing a given learning task. Rather, they are given an unexpected test based on the goal once the task is completed.

Most language teachers agree that second/foreign language learners would have to acquire their first few thousand words intentionally since they lack enough proficiency in the target language to just "pick up" the meaning of the new words. However, according to Shokouhi (2009), most vocabulary is acquired incidentally later on in the learning process since it occurs as a result of other activities - especially those related to reading, intensive or extensive. This was also emphasized by Nation (1997) who maintained that by involving the learners in listening or reading comprehension tasks, teachers can help promote their students' incidental vocabulary learning. According to Waring and Takaki (2003) and Brown, Waring and Donekaewbua (2008), a word has to be met ten to fifteen times or more, to be learned incidentally by reading graded material, and even so, the retention might not last longer than 3 months. To learn new words, what is needed is "... repeated and consistent exposure to graded readers" (Waring and Takaki, 2003, p. 154).

\subsection{Incidental Vocabulary Learning and ER}

ER means learning to read by being involved in reading comprehension activities (Ellis, 1995; Nation, 2005; Lee, 2007; Cramer, Ascough, Williams, and Loucky, 2007). This aim can only be achieved by reading a large number of texts out of the classroom. Besides, learners can choose and read reading materials based on their own interest, with the aim of general comprehension rather than translation or analysis of vocabulary and grammatical points.

Nation and Wang (as cited in Nation, 2005) mention six conditions for an ER program to be successful in providing students with opportunities for incidental vocabulary learning; reading at least one graded reader every week, reading at least read five books in each level before moving on to the next, reading more books at higher levels, reading 15-20 graded readers every year, studying vocabulary directly or using of a dictionary in early stages, and reading graded readers up to the very last level. An ER program that can account for all the above mentioned criteria can thus help improve intentional vocabulary acquisition. Two such programs are described below.

\subsection{ER Programs}

So far, several ER-promoting programs have been suggested and used, two of which having been more successful than others: the Accelerated Reader (Paul, VanderZee, Rue, \& Swanson, 1996) and the MoodleReader (Robb, 2005).

\subsubsection{The Accelerated Reader}

In the early 1990s the computerized program known as the Accelerated Reader was introduced by Paul, VanderZee, Rue, \& Swanson, (1992). Using the Accelerated Reader (henceforth AR), language learners go through three stages. First, they are required to read a book, fiction, non-fiction, subject matter textbook, or magazine. Having finished their books, the learners log in to the AR software and take quizzes on the material they have studied, which are available in the software database for each title. The information regarding each learner is delivered to the teacher at the end of the program.

\subsubsection{The MoodleReader}

Although the AR was working well for several language teachers and ER practitioners, it was not without its problems. One of the shortcomings according to Robb (2010) was the inability to add quizzes for newly published graded readers. Another major problem was the fact that the quiz questions were not randomized, and all students got the same questions which in turn, caused the problems of quiz security and cheating. In response to these shortcomings, Robb (2005) created the MoodleReader.

The MoodleReader is a database of over 1600 online quizzes on graded readers from different series and publications (Oxford Series, Cambridge, Macmillan, Cengage/Heinle and Penguin to name just a few), developed at Kyoto Sangyo University, Japan. The program carefully follows the ER approach by exposing ESL/EFL learners to a large amount of reading materials. After reading a book at their own level and choice of genre and title, learners are able to take their quizzes by logging in to the system at anytime, from anywhere. Teachers can set a time limit for completion of each quiz and control the book level suitable for each student. Moreover, the questions are randomized so that each student receives question sets which are different from those of other students. The positive and practical features of the MoodleReader, as well as its ease of use and convenience make it a useful tool to 


\section{implement ER in any ESL context.}

\subsection{Vocabulary Learning Strategies}

According to Marefat (2003), as the concept of language learning strategies has emerged, several attempts have been made in order to provide a relationship between these strategies and language learning tasks "believing that each strategy enhances learning of vocabulary, pronunciation, or improves reading and speaking skills" (p. 48). Moreover, O'Malley, Chamot, Stewner-Manzanares, Russo, and Kupper (1985) state that language learning strategies are mostly used for vocabulary-related learning tasks.

$\mathrm{Gu}$ (2010) defines vocabulary learning strategies as tools which enable language learners to make proper decisions about what to learn and how to learn it. Of course, second/foreign language learners employ various strategies in order to acquire vocabulary items of their target language. Consequently, different researchers have categorized vocabulary learning strategies in various ways. Instances of such categorizations are provided by Gu and Johnson (1996), Schmitt (1997), and Nation (2011).

Based on Gu and Johnson (1996), vocabulary learning strategies are classified into four groups; metacognitive, cognitive, memory, and activation strategies. Metacognitive strategies, include selective attention as well as self-initiation strategies. Cognitive strategies include use of dictionaries, guessing and note taking strategies. Memory strategies consist of rehearsal and encoding strategies. Finally, activation strategies are those that learners utilize in order to use the new words in various contexts.

Schmitt (1997) classifies vocabulary learning strategies into two groups, the first of which includes strategies which determine the meaning of new vocabulary items which the learners face for the first time, and contains determination and social strategies. The second group, on the other hand, entails strategies which consolidate the meaning of vocabulary items when encountered again by the learners. This group consists of cognitive, metacognitive, memory, and social strategies.

Another taxonomy of vocabulary learning strategies is developed by Nation (2011) who classifies the strategies into three categories of planning, source, and process. Planning, he states, engages the learners in making decisions on where, how, and how often to focus their attention on vocabulary items. Source refers to obtaining information about the word and process establishes the knowledge of vocabulary items through noticing, retrieving, and generating strategies.

\section{Objectives of the Present Study}

Despite spending several years learning the foreign language, many foreign language learners do not have rich lexicons. Finding ways to help them improve their vocabulary knowledge, therefore, gains importance. Engaging EFL learners in ER programs is considered to be one of the valuable mediums for improving incidental vocabulary acquisition.

By reviewing the research carried out in the field of TEFL, however, one can notice that little attention has been heeded to the impact of ER on the foreign language learners' incidental vocabulary acquisition in Iran. By conducting this study, the researchers are willing to find out whether incidental vocabulary learning occurs as a result of ER activities, and how ER affects the recognition or production of incidentally learnt vocabulary items. Moreover, the effect of the student's use of vocabulary learning strategies on their incidental vocabulary learning will be examined. In line with the above mentioned objectives, the research questions were formulated as follows:

1. Does involving foreign language learners in ER by using the MoodleReader promote their incidental vocabulary acquisition?

2. If involving foreign language learners in ER promotes their incidental vocabulary acquisition, what kind of knowledge will it affect more, vocabulary recognition or production?

3. Is there any relationship between incidental vocabulary learning and the students' use of learning strategies?

\section{Method}

\subsection{Participants}

The participants of this study were 38 Iranian male and female sophomores majoring in English Language and Literature at Shiraz University, Iran, randomly assigned to experimental $(\underline{n}=20)$ and control $(\underline{n}=18)$ groups.

\subsection{Instruments}

In line with the objectives of the study and the research questions, the following instruments were used:

3.2.1 Nation and Beglar's (2007) Production and Laufer and Nation's (1999) Recognition Vocabulary Levels Tests

These tests each consist of 5 sections including the 2000,3000, 5000, 10,000 word levels, and an academic subtest. 
The first part (2000 level) of each test consists of high frequency words, which are mostly used in informal conversations. The next two sections (3000 and 5000), however, cover vocabulary items of a lower frequency list. Finally, the last two parts (10000 and academic) include mostly specialized words which are not normally used in daily language use and are important only in academic settings.

\subsubsection{The Oxford Placement Test}

The second instrument employed in the present study was the Oxford Placement Test (OPT), used to determine the proficiency level of English. The Oxford Placement Test, which was originally published in 1982 by Allen, evaluates a test taker's capability to understand grammatical forms and the meanings they convey in various contexts. It also measures the extent to which learners can use these language resources to communicate in English language situations.

\subsubsection{Vocabulary Learning Strategies Questionnaire}

The third instrument of the research was the Vocabulary Learning Strategies questionnaire, developed by Kudo (1999). This questionnaire includes two sections. The first on the participants' demographic information, and the second questions about the strategies they have used to learn vocabulary. The questions are classified into four categories dealing with social, memory, cognitive, and meta-cognitive strategies.

\subsubsection{A MoodleReader Course}

A MoodleReader course was set up for the students of the experimental group. As mentioned before, this website provides on-line quizzes on over 1600 graded readers and books for young and adult readers. Students read a graded reader according to their level, login to the program and take an online quiz made consisting of 10 randomized questions.

\subsubsection{Graded Readers}

Approximately 250 graded readers from different publications (Oxford, Cambridge, Penguin, Macmillan and Heinemann) and 8 levels (easy starters to level 6) were purchased for the experimental group of this study, and kept in the researcher's office for students to borrow on a weekly basis.

\subsection{Procedure}

At the beginning of the semester, the OPT and the Vocabulary Levels Tests were administered to the students of both groups to ensure their equality. A MoodleReader course was then created to promote ER for the experimental group whose members were required to enroll in and take at least 12 quizzes in a period of 3.5 months according to their language level (as determined by the OPT and the Levels Tests), availability of book title, and personal choice of genre. Completion of the 12-book MoodleReader program carried 30\% of their final grade. The MoodleReader quizzes consisted of 10 questions each; $4 \mathrm{MC}, 2$ who-said, $3 \mathrm{~T} / \mathrm{F}$ and 1 ordering items.

The control group, on the other hand, was required to follow the traditional ER activities of the department. At the beginning of the term, four graded readers were selected by the instructors and assigned to students to read as their ER material. The titles and levels of these books were the same for all students, and no choice whatsoever was allowed. Students were given fixed dates for quizzes on these books with a 20-25 day interval between each, the results of which formed $30 \%$ of their final grade. These quizzes consisted of 30 questions on the general plot of the story with $\mathrm{MC}$, who-said, $\mathrm{T} / \mathrm{F}$ and fill-in-the-blank item types (no fixed number for the item types were specified). Quizzes were paper based and therefore not randomized, so all students answered the same questions. At the end of the semester, students from both groups were given the two Production and Recognition Vocabulary Levels tests again to see whether using the MoodleReader had resulted in any significant difference between the two groups in terms of their vocabulary knowledge.

\section{Results and Discussion}

In this section, each research question is stated once again, followed by the data analyses required to answer it. The findings of the study are then presented and discussed with reference to previous research.

\section{1- Does involving foreign language learners in ER by using the MoodleReader promote their incidental vocabulary acquisition?}

In order to compare the means of the vocabulary recognition as well as the vocabulary production pretests and posttests of the experimental and control groups, four independent $t$-tests were run. As the first table shows, for both pretests, the differences between the means of the two groups were not significant, indicating that the two groups' levels of recognition and production vocabularies were similar at the beginning of the experiment. However, the results of the posttests indicate that the means obtained by the students in the experimental group on the recognition 
and production tests were significantly higher than those of the control group, $\underline{t}(36)=2.49$ for recognition and $t(36)$ $=5.37$ for production.

These findings suggest that using the MoodleReader affected the students' incidental acquisition of vocabulary, and are in line with Day, Omura, and Hiramatsu (1991), and Dupuy and Krashen (1993) who found significant improvements in student vocabulary gains after implementing ER programs in their contexts, even though the amount of exposure for the participants in their studies to new words was much smaller as compared to the present work; in the Day, Omura, and Hiramatsu study, students were exposed to 1032 words, and in Dupuy and Krashen, to only 15 pages of text, whereas the students in the present study were to read at least 150,000 words for the semester.

In order to see if each group improved their vocabulary knowledge throughout the experiment, irrespective of the ER program they participated in, four matched $t$-tests were run. As indicated in Table 2, the experimental group showed significant improvement in their performances on both recognition and production vocabulary tests, indicating that they benefited from using the MoodleReader to acquire new words. In addition, the control group, too, showed improvement in the scores on the vocabulary production tests, implying that the traditional ER program also contributed to vocabulary acquisition, though not as much as compared to the MoodleReader. Another factor contributing to this finding can be intensive reading program itself, during which vocabulary and reading strategies are learnt (and taught) explicitly, a conclusion that is supported by numerous works including Paribakht and Wesche (1997), Zimmerman (1997) and Laufer (2006), who maintained that vocabulary instruction can help produce long-term significant results in vocabulary gains of ESL students. Nevertheless, as Table 1 shows, the experimental group had better gains in vocabulary. In addition, the effect sizes calculated for gains in recognition and production vocabularies, (Table 2), indicate that the magnitude of difference between the pretests and posttests of productive vocabulary for the control group was 0.4 , which is a moderate effect size, while that of the experimental group was 0.85 , which is a large effect size. This indicates that the MoodleReader program was more effective than the traditional method and contributed more to vocabulary acquisition.

2- If involving foreign language learners in ER promotes their incidental vocabulary acquisition, what kind of knowledge will it affect more, vocabulary recognition or production?

In order to determine what kind of vocabulary knowledge was affected more by the experiment, the experimental group's recognition and production vocabulary gains were compared. As table 3 shows, the mean gains for recognition and production vocabularies of the experimental group are 2.3 and 10.72 , respectively. In order to determine whether the difference observed between the means was significant or not, a matched t-test was run to compare the recognition and the production gains of the experimental group, the results of which are presented in Table 4. As shown in this table, the difference between the means is significant $(\mathrm{p}=.000)$. Moreover, as the mean obtained for the production gain is higher, it can be concluded that the experiment has affected production vocabulary gains more than recognition. The effect size was also computed in order to determine the magnitude of the difference. It was found to be 0.6 which is considered a large effect size, indicating that the treatment highly affected the experimental group's production vocabulary.

As these results suggest, the experimental group's gain scores for vocabulary recognition were already high at the beginning of the experiment and did not improve greatly at the end of the program, a finding which might be attributed to the ceiling effect implying that the members of this group had a high level of vocabulary knowledge from the beginning. Thus, the improvement observed in their vocabulary recognition was not too high. Regarding production vocabulary, however, the learners had obtained quite low scores at the beginning of the experiment but improved significantly at the end, hence showing the effectiveness of the experiment on this aspect of incidental vocabulary acquisition.

Comparing the mean gains obtained for the experimental group's recognition and production vocabulary ( 2.3 and 10.72) with those of the control group (1.7 and 2.6), one notices that the experimental group showed more progress in production vocabulary in comparison to the control group. It can be concluded, therefore, that using the MoodleReader for the ER program can promote production vocabulary knowledge. This finding is in line with those of Laufer (1992), and Haynes and Baker (1993) who showed that ER tasks help promote incidental vocabulary acquisition as well as retention. The great effect of ER programs on both acquisition and production of vocabulary items is also emphasized by Simcock (as cited in Newton, 1995) and Joe (as cited in Newton, 1995).

\section{3- Is there any relationship between incidental vocabulary learning and the students' use of learning strategies?}

To answer this question, first the two group's mean gains for both recognition and production vocabularies were calculated. Four multiple regression tests were run next, the first of which aiming to find out if there was a relationship between the control group's recognition vocabulary and their use of vocabulary learning strategies. 
As the table 5 shows, no significant relationship was found between the control group's recognition vocabulary and their vocabulary learning strategy use $(\mathrm{p}=.298)$.

The second regression test was then conducted on the effect of the control groups' use of vocabulary learning strategies on their production vocabulary (Table 6).

The findings show no significant relationship between the control group's knowledge of production vocabulary and their use of vocabulary learning strategies $(\mathrm{p}=.805)$.

Another regression test was run in order to determine the relationship between the experimental group's recognition vocabulary and their use of vocabulary learning strategies (Table 7).

Table 7 shows that the experimental group's recognition vocabulary was not affected by their use of vocabulary learning strategies significantly $(\mathrm{p}=.956)$.

Finally, the last regression test was conducted in order to find the effect of the experimental group's use of vocabulary learning strategies and their production vocabulary (Table 8).

As the table reveals, a significant relationship was found between the experimental group's use of vocabulary learning strategies and their knowledge of production vocabulary $(\mathrm{p}=.005)$. To determine the extent to which the learners' use of learning strategies has affected their production vocabulary, the model summary and the coefficients were taken into account. Results appear in Tables 9 and 10, respectively.

The results above show that for every unit of increase in strategy use, 0.55 unit of change in productive vocabulary knowledge is observed. In other words, $55 \%$ of the change in the vocabulary gain is accounted for by strategy use, a finding which is in line with $\mathrm{Gu}$ (2003), who views vocabulary acquisition as a dynamic process engaging meta-cognitive choices as well as the cognitive implementation of vocabulary learning strategies. Thus, vocabulary learning strategies are considered to be great facilitators of second/foreign vocabulary acquisition. Several researchers have provided supporting evidence for the above finding.

Cook (as cited in Zarei and Tagipour Arasteh, 2011), for example, believes the following strategies to be highly effective on learning the vocabulary items: "guessing from context, using a dictionary, making deductions from the word-form, linking to cognates, repetition and rote learning, organizing words in the mind, and linking to existing knowledge" (p. 97). In the same line, Nation (2011) states that guessing helps competent readers a great deal in order to acquire more vocabulary knowledge from context. The effect of guessing strategies on the learners' text comprehension has also been confirmed by other researchers (Haynes, 1993; Morrison, 1996; Laufer and Sim, 1985) and a strong relationship is believed to exist between guessing skills, vocabulary knowledge, and reading skills (Herman, Anderson, Pearson, and Nagy, 1987).

Research also shows vocabulary learning strategies, particularly contextualization, to be of great help in the process of vocabulary acquisition (Thornbury, 2003; Wei, 2007). This, according to Zarei and Tagipour Arasteh (2011), might be due to the fact that using this strategy enables the learners to use the contextual clues in order to find out the meanings of the new words they encounter.

Despite the above mentioned findings related to the experimental group's productive vocabulary, no significant relationships were found between vocabulary learning strategies and the experimental group's recognition vocabulary, the control group's recognition and production vocabulary. This finding might be related to the learners' lack of awareness of the importance of vocabulary learning strategies. As Suberviola and Mendez (2002) mention "the knowledge of how words are settled in our mental dictionary provides very valuable clues on how to organize our teaching, and the strategies we want our students to develop depend greatly on this knowledge of how this new vocabulary is going to settle in the learners' minds" (p.247). Research also shows the important effect of explicitly teaching vocabulary learning strategies on the learners' acquisition, storage, and retrieval of vocabulary items (Suberviola and Mendez, 2002; Nemati, 2009). Thus, it is helpful to make the learners aware of such strategies so that they put them to use for internalizing the new words they encounter during their ER programs.

\section{Limitations of the Study}

This study has not been without its limitations. First, the number of students in each group was too small, which limits the generalizability of the results. Second, several variables which might have contributed to the findings and results of the present study, such as book length, level, genre and choice of title and time interval between tests were not accounted for the control group. Finally, other factors and elements related to the language learning context (age, sex, language background, etc.) which could have had a potential effect of the outcomes of this study were not controlled. It is suggested that these factors be considered in future replications of the present study. 


\section{Conclusion}

The present research aimed at answering three questions. The first question was whether involving foreign language learners in ER by using the MoodleReader promoted their incidental vocabulary acquisition or not. The answer to this question, as the statistics show was positive, in the sense that students who received the MoodleReader treatment did show higher and larger gains in their incidental vocabulary acquisition. The findings also suggest that for the second research question regarding the affect of the treatment on different kinds of vocabulary knowledge, i.e. recognition and production, the treatment helped the experimental group improve their production vocabulary more as compared to the control group. Their recognition vocabulary, however, did not improve significantly after their use of the MoodleReader. As for the third research question, addressing the relationship between incidental vocabulary learning and the students' use of learning strategies, the results indicate that the only significant relationship was found between the experimental group's use of vocabulary learning strategies and their production vocabulary. Other relationships (control group's strategy use and both production and recognition vocabulary, as well as the experimental group's strategy use and recognition vocabulary) were found to be insignificant.

The findings of the study are remarkable in that they provide EFL teachers with information regarding the relationship between students' exposure to large quantities of reading material via MoodleReader and the extent to which vocabulary items are learnt incidentally during such an extensive reading program. The results can also encourage the classroom teacher to create an English language learning context outside the class for students to participate in at their own pace, level, and interest. Once the logistics of creating a small library of graded readers are dealt with, using the MoodleReader for an extensive reading program can create such a context which is both easy to administer and monitor across large groups of students.

\section{References}

Brown R., Waring R., \& Donekaewbua S. (2008). Incidental vocabulary acquisition from reading, reading-while-listening, and listening to stories. Reading in a foreign language, 20(2). Retrieved January 5, 2011, from http://www.nflrc.hawaii.edu/rfl/October2008/brown/brown.pdf

Chen, Y. (2009). A cognitive linguistic approach to classroom English vocabulary instruction for EFL learners in Mainland China. English Language Teaching, 2(1), 95-100.

Cramer, T., Ascough, R. K., Williams, D., \& Loucky, J. P. (2007). Extensive reading forum: Motivation and community through extensive reading. RELC Journal, 38(2), 133-149.

Day, R. R., Omura, C., \& Hiramatsu, M. (1991). Incidental EFL vocabulary learning and reading. Reading in a Foreign Language, 7, 541-551.

Dupuy, B., \& Krashen, S. D. (1993). Incidental vocabulary acquisition in French as a foreign language. Applied Language Learning, 4(1), 55-63.

Ellis, N. C. (1995). The psychology of foreign language vocabulary acquisition: Implications for CALL. Computer Assisted Language Learning, 8, 103-128. (January 5, 2011). http://dx.doi.org/10.1080/0958822940080202

Gu, Y. (2003). Vocabulary Learning in a Second Language. Person, Task, Context, and Strategies. TESOL-EJ, 7(2), $1-26$.

Gu, Y. (2010). Learning Strategies for Vocabulary Development. Reflections on English Language Teaching, 9(2), 105-118.

Gu, Y., \& Johnson, R. K. (1996). Vocabulary Learning Strategies and Language Learning Outcomes. Language Learning, 46(4), 643-679. http://dx.doi.org/10.1111/j.1467-1770.1996.tb01355.x

Hamzah, M. S. G., Kafipiur, R., \& Abdullah, S. K. (2009). Vocabulary learning strategies of Iranian undergraduate EFL students and its relation to their vocabulary size. European Journal of Social Sciences, 11(1), 39-50.

Haynes, M. (1993). Patterns and perils of guessing in second language reading. In T. Huckin, M. Haynes, M., \& J. Coady (Ed.), Second language reading and vocabulary learning (pp. 46-64). Norwood, N.J.: Ablex.

Haynes, M., \& Baker, I. (1993). American and Chinese readers learning from lexical familiarization in English texts. In T. Huckin, M. Haynes \& J. Coady (Eds.), Second language reading and vocabulary acquisition (pp. 130-152). Norwood, NJ: Ablex.

Herman, P. A., Anderson, R. C., Pearson, P. D., \& Nagy, W. E. (1987). Incidental acquisition of word meaning from expositions with varied text features. Reading Research Quarterly, 22, 263-264. http://dx.doi.org/10.2307/747968

Kudo, Y. (1999). L2 vocabulary learning strategies. Honolulu: University of Hawaii, Second Language Teaching \& Curriculum Center. Retrieved January 29, 2011, from http://nflrc.hawaii.edu/NetWorks/NW14.pdf 
Laufer, B. (2006). Vocabulary acquisition in a second language: Do learners really acquire most vocabulary by reading? Some empirical evidence. The Canadian Modern Language Review, 59(4), 565-585.

Laufer, B. (1992). How much lexis is necessary for reading comprehension? In H. Bejoint \& P. Arnaud (Eds.), Vocabulary and applied linguistics (pp.126-132). Basingstoke \& London: Macmillan.

Laufer, B., \& Nation, I. S. P. (1999). A vocabulary size test of controlled productive ability. Language Testing, 16, 33-51. http://dx.doi.org/10.1177/026553229901600103

Laufer, B., \& Sim, D. D. (1985). Taking the easy way out: Non-use and misuse of clues in EFL reading. English Teaching Forum, 23(2), 7-10.

Lee, S. (2007). Revelations from Three Consecutive Studies on Extensive Reading. RELC Journal, 38(2), 150-170. (October 4, 2010). http://dx.doi.org/10.1177/0033688207079730

Marefat, H. (2003). The Impact of Teaching Direct Learning Strategies on the Retention of Vocabulary by EFL Learners. The Reading Matrix, 3(2), 47-61.

Morrison, L. (1996). Talking about words: A study of French as a second language learner's lexical inferencing procedures. Canadian Modern Language Review, 53, 41-75.

Nakata, T. (2006). Implementing optimal spaced learning for English vocabulary learning: Towards improvement of the Low-First Method derived from the reactivation theory. JALT CALL Journal, 2(2), 19-36.

Nation, P. (2011). Learning vocabulary in another Language (13th ed.). Cambridge: Cambridge University Press.

Nation, P. (2005). Vocabulary Learning through Extensive Reading. In G. Poedjosoedarmo (ed.), Innovative Approaches to Reading and Writing (pp.10-21). RELC Anthology Series 46. RELC, Singapore.

Nation, I. S. P. (1997). The language learning benefits of extensive reading. The Language Teacher, 21(5), 13-16.

Nation, I. S. P., \& Beglar, D. A. (2007). A vocabulary size test. The Language Teacher, 31(7), 9-13. Retrieved January, 10, 2011 from http://jalt-publications.org/tlt/resources/2007/0707a.pdf

Nemati, A. (2009). Memory Vocabulary Learning Strategies and Long-term Retention. International Journal of Technical Education, 1(2), 14-24.

Newton, J. (1995). Task-based interaction and incidental vocabulary learning: A case study. Second Language Research, 11, 159-177. http://dx.doi.org/10.1177/026765839501100207

O'Malley, J. M., Chamot, A. U., Stewner-Manzanares, G., Kupper, L. \& Russo, R. P. (1985), Learning strategies used by beginning and intermediate ESL students. Language Learning, 35, 21-46. http://dx.doi.org/10.1111/j.1467-1770.1985.tb01013.x

Paribakht, T. S., \& Wesche, M. (1997). Vocabulary Enhancement Activities and Reading for Meaning in Second Language Vocabulary Development. In J. Coady and T. Huckin (eds.), Second Language Vocabulary Acquisition: A Rationale for Pedagogy. Cambridge: Cambridge University Press, 174-200.

Paul, T. S., VanderZee, D., Rue, T., \& Swanson, S. (1996). Impact of the accelerated reader technology-based literacy program on overall academic achievement and school attendance. Paper presented at the Literacy and Technology for the 21th Century conference of the National Reading Research Center, Atlanta, GA.

Pigada, M., \& Schmitt, N. (2006). Vocabulary acquisition from extensive reading: A case study. Reading in a Foreign Language, 18, 1-28.

Robb, T. N. (2005). Outline of MoodleReader features. Retrieved December 10, 2010, from http://moodlereader.org $/$ moodle $/ \mathrm{mod} /$ resource $/$ view.php?inpopup=true\&id=3521

Robb, T. N. (2010). Getting Them to Read Outside of Class: Let Moodle Be the Enforcer! MEXTESOL Journal, 34(2), 1-7.

Shokouhi, H. (2009). Learners' incidental vocabulary acquisition: A case on narrative and expository texts. English Language Teaching, 2(1), 13-23.

Schmitt, N. (2008). Review article: Instructed second language vocabulary learning. Language Teaching Research, 12(3), 329-363. http://dx.doi.org/10.1177/1362168808089921

Schmitt, N. (1997). Vocabulary learning strategies. In N. Schmitt \& M. McCarthy. (Eds.), Vocabulary: Description, acquisition, and pedagogy. New York: Cambridge University Press.

Suberviola, E. S., \& Mendez, R. V. (2002). Vocabulary acquisition strategies. Didactica (Lengua y Liteatura), 14, 233-250. 
Thornbury S. (2003). Teaching vocabulary using short texts. Asian EFL J., 5(2), 230-234.

Waring, R., \& Takaki, M. (2003). At what rate do learners learn and retain new vocabulary from reading a graded reader? Reading in a Foreign Language, 15(2), 131-163. Retrieved January 5, 2012, from http://nflrc.hawaii.edu/rfl/October2003/waring/waring.pdf

Wei M. (2007). An Examination of Vocabulary Learning of College-level Learners of English in China. Asian EFL J., 9(2), 93-114.

Zimmerman, C. B. (1997). Do reading and interactive vocabulary instruction make a difference? An empirical study. TESOL Quarterly, 31, 121-140. http://dx.doi.org/10.2307/3587978

Zarei, A. A., \& Arasteh Tagipour, S. (2011). The effects of code-mixing, thematic clustering, and contextualization on L2 vocabulary recognition and production. Journal of Languages and Culture, 2(6), 96-102.

Table 1. Results of t-test for the difference between the two groups on vocabulary production and recognition $(\mathrm{p}<$ $0.05)$

\begin{tabular}{|c|c|c|c|c|c|c|}
\hline Group & $\mathrm{n}$ & $\mathrm{M}$ & SD & $\mathrm{t}$ & $\mathrm{df}$ & Sig (2-tailed) \\
\hline $\begin{array}{l}\text { Rec1 } \\
\text { control } \\
\exp \\
\end{array}$ & $\begin{array}{l}18 \\
20\end{array}$ & $\begin{array}{l}20.75 \\
21.34\end{array}$ & $\begin{array}{l}4.35 \\
4.18\end{array}$ & .42 & 36 & .676 \\
\hline $\begin{array}{l}\operatorname{Rec} 2 \\
\text { control } \\
\exp \end{array}$ & $\begin{array}{l}18 \\
20\end{array}$ & $\begin{array}{l}19.25 \\
23.35\end{array}$ & $\begin{array}{l}5.10 \\
5.02\end{array}$ & 2.49 & 36 & $.018^{*}$ \\
\hline $\begin{array}{l}\text { Pro1 } \\
\text { control } \\
\text { exp }\end{array}$ & $\begin{array}{l}18 \\
20\end{array}$ & $\begin{array}{l}7.56 \\
7.92\end{array}$ & $\begin{array}{l}2.38 \\
2.52\end{array}$ & .44 & 36 & .661 \\
\hline $\begin{array}{l}\text { Pro2 } \\
\text { control } \\
\exp \\
\end{array}$ & $\begin{array}{l}18 \\
20\end{array}$ & $\begin{array}{l}10.20 \\
17.93\end{array}$ & $\begin{array}{l}3.92 \\
4.83\end{array}$ & 5.37 & 36 & $.000^{*}$ \\
\hline
\end{tabular}

Table 2. Results of t-test $\mathrm{s}$ for the difference between the pretests and posttests of recognition and production vocabulary for each group. $(\mathrm{p}<0.05)$

\begin{tabular}{|c|c|c|c|c|c|}
\hline Groups & $\mathrm{M}$ & $\mathrm{t}$ & $\mathrm{df}$ & Sig. & Effect size \\
\hline \multirow{2}{*}{$\begin{array}{l}\text { Rec1cont } \\
\text { Rec2cont }\end{array}$} & 20.75 & \multirow[t]{2}{*}{1.94} & \multirow[t]{2}{*}{17} & \multirow[t]{2}{*}{0.06} & \\
\hline & 19.25 & & & & \\
\hline \multirow{2}{*}{$\begin{array}{l}\text { Rec1exp } \\
\text { Rec2exp }\end{array}$} & 21.34 & \multirow[t]{2}{*}{3.32} & \multirow[t]{2}{*}{17} & \multirow[t]{2}{*}{0.00} & \\
\hline & 23.35 & & & & \\
\hline \multirow{2}{*}{$\begin{array}{l}\text { Prod1 cont } \\
\text { Prod2cont }\end{array}$} & 7.56 & \multirow[t]{2}{*}{3.38} & \multirow[t]{2}{*}{17} & \multirow[t]{2}{*}{0.00} & \multirow[t]{2}{*}{0.4} \\
\hline & 10.20 & & & & \\
\hline \multirow{2}{*}{$\begin{array}{l}\text { Prod 1 exp } \\
\text { Prod2exp }\end{array}$} & 7.92 & \multirow[t]{2}{*}{10.10} & \multirow[t]{2}{*}{17} & \multirow[t]{2}{*}{0.00} & \multirow[t]{2}{*}{0.85} \\
\hline & 17.93 & & & & \\
\hline
\end{tabular}

Table 3. Descriptive Statistics for the experimental group's vocabulary gains

\begin{tabular}{|l|l|r|r|r|r|}
\hline \multicolumn{2}{|c|}{} & Mean & N & Std. Deviation & \multicolumn{1}{c|}{ Std. Error Mean } \\
\hline \multirow{2}{*}{ Pair 1 } & Exp. Rec. gain & 2.3889 & 18 & 3.04822 & .71847 \\
\cline { 2 - 6 } & Exp. Prod. gain & 10.7222 & 18 & 4.50105 & 1.06091 \\
\hline
\end{tabular}


Table 4. Paired Sample t-test comparing the experimental group's recognition and production vocabulary gains

\begin{tabular}{|c|c|c|c|c|c|c|c|c|c|}
\hline & & \multicolumn{5}{|c|}{ Paired Differences } & \multirow[b]{3}{*}{$\mathrm{t}$} & \multirow[b]{3}{*}{$\mathrm{df}$} & \multirow{3}{*}{$\begin{array}{c}\text { Sig. } \\
\text { (2-tailed) }\end{array}$} \\
\hline & & \multirow[b]{2}{*}{ Mean } & \multirow{2}{*}{$\begin{array}{c}\text { Std. } \\
\text { Deviation }\end{array}$} & \multirow{2}{*}{$\begin{array}{l}\text { Std. } \\
\text { Error } \\
\text { Mean }\end{array}$} & \multicolumn{2}{|c|}{$\begin{array}{c}95 \% \text { Confidence } \\
\text { Interval of the } \\
\text { Difference }\end{array}$} & & & \\
\hline & & & & & Lower & Upper & & & \\
\hline $\begin{array}{l}\text { Pair } \\
1\end{array}$ & $\begin{array}{l}\text { Rec. Exp gain - } \\
\text { Prod. Exp gain }\end{array}$ & 8.33333 & 6.10149 & 1.43814 & 11.36754 & 5.29913 & 5.795 & 17 & .000 \\
\hline
\end{tabular}

Table 5. ANOVA for the relationship between the control group's recognition vocabulary and their use of vocabulary learning strategies

\begin{tabular}{|l|l|l|l|l|l|l|}
\hline \multicolumn{2}{|l|}{ Model } & Sum of Squares & df & Mean Square & F & Sig. \\
\hline \multirow{4}{*}{1} & Regression & 16.798 & 1 & 16.798 & 1.207 & .298 \\
\cline { 2 - 8 } & Residual & 139.132 & 10 & 13.913 & & \\
\cline { 2 - 7 } & Total & 155.930 & 11 & & & \\
\hline
\end{tabular}

Table 6. ANOVA for the relationship between the control group's production vocabulary and their use of vocabulary learning strategies

\begin{tabular}{|l|l|l|l|l|l|l|}
\hline \multicolumn{2}{|l|}{ Model } & Sum of Squares & df & Mean Square & F & Sig. \\
\hline \multirow{4}{*}{1} & Regression & 1.095 & 1 & 1.095 & .064 & .805 \\
\cline { 2 - 8 } & Residual & 170.275 & 10 & 17.027 & & \\
\cline { 2 - 7 } & Total & 171.370 & 11 & & & \\
\hline
\end{tabular}

Table 7. ANOVA for the relationship between the experimental group's recognition vocabulary and their use of vocabulary learning strategies

\begin{tabular}{|l|l|l|l|l|l|l|}
\hline \multicolumn{2}{|l|}{ Model } & Sum of Squares & $\mathrm{df}$ & Mean Square & $\mathrm{F}$ & Sig. \\
\hline \multirow{4}{*}{1} & Regression & .044 & 1 & .044 & .003 & .956 \\
\cline { 2 - 8 } & Residual & 138.556 & 10 & 13.856 & & \\
\cline { 2 - 7 } & Total & 138.600 & 11 & & & \\
\hline
\end{tabular}

Table 8. ANOVA for the relationship between the experimental group's production vocabulary and their use of vocabulary learning strategies

\begin{tabular}{|l|l|l|l|l|l|l|}
\hline \multicolumn{2}{|l|}{ Model } & Sum of Squares & df & Mean Square & F & Sig. \\
\hline \multirow{4}{*}{1} & Regression & 179.036 & 1 & 179.036 & 12.501 & $.005^{\text {a }}$ \\
\cline { 2 - 7 } & Residual & 143.214 & 10 & 14.321 & & \\
\cline { 2 - 7 } & Total & 322.250 & 11 & & & \\
\hline
\end{tabular}


Table 9. Model summary for the regression test on the relationship between the experimental group's production vocabulary and their use of learning strategies

\begin{tabular}{|l|l|l|l|l|}
\hline Model & R & R Square & Adjusted R Square & Std. Error of the Estimate \\
\hline 1 & $.745^{\mathrm{a}}$ & .556 & .511 & 3.78437 \\
\hline
\end{tabular}

Table 10. Coefficient for the effect of vocabulary learning strategies on the experimental group's production vocabulary

\begin{tabular}{|c|c|c|c|c|c|c|}
\hline & & \multicolumn{2}{|c|}{ Unstandardized Coefficients } & \multirow{2}{*}{\begin{tabular}{|l} 
Standardized \\
Coefficients \\
Beta \\
\end{tabular}} & \multirow[b]{2}{*}{$\mathrm{t}$} & \multirow[b]{2}{*}{ Sig. } \\
\hline \multicolumn{2}{|c|}{ Model } & B & Std. Error & & & \\
\hline \multirow[t]{2}{*}{1} & (Constant) & -5.824 & 4.813 & & -1.210 & .254 \\
\hline & Strategy mean & 5.153 & 1.457 & .745 & 3.536 & .005 \\
\hline
\end{tabular}

